\title{
LAS COMPETENCIAS DEL TRADUCTOR JURÍDICO: REPASO Y REFLEXIÓN
}

\section{AS COMPETÊNCIAS DO TRADUTOR JURÍDICO: REVISÃO E REFLEXÃO}

\section{Rubén González Vallejo*}

\begin{abstract}
RESUMEN
El presente artículo se presenta como una reflexión sobre la formación del traductor jurídico con el objetivo de plantear los pilares necesarios para la preparación del ejercicio de la profesión que a tal fin ha considerado la literatura de especialidad. Inicialmente abordaremos el eterno debate sobre si el traductor jurídico debe ser o no jurista desde los tres puntos de vista clasistas. A continuación, se detallarán las competencias del traductor y los papeles que puede desempeñar durante su cometido, destacando los componentes formativos y temáticos más importantes que ha de desarrollar el traductor de textos legales y las técnicas de traducción que deberá integrar para satisfacer las necesidades del documento final.

Palabras clave: competencias traductoras; lenguaje jurídico; técnicas de traducción.
\end{abstract}

\section{RESUMO}

Este artigo é uma reflexão sobre a formação do tradutor jurídico com o objetivo de estabelecer os pilares necessários para a preparação do exercício da profissão que considerou a literatura de especialidade para esse fim. Inicialmente, abordaremos o eterno debate sobre se o tradutor jurídico deve ou não ser um advogado, considerando os três pontos de vista classistas. Em seguida, detalharemos as competências do tradutor e os papéis que ele pode desempenhar durante sua tarefa, destacando os componentes mais importantes de treinamento e assuntos que o tradutor jurídico deve desenvolver, e as técnicas de tradução que deve integrar a fim de atender às necessidades do documento final.

Palavras-chave: competências tradutórias; linguagem jurídica; técnicas de tradução.

\section{INTRODUCCIÓN}

El lenguaje jurídico es una variedad de la lengua común que subyace con rasgos fuertemente marcados al ser reflejo de la evolución de las sociedades que lo vieron nacer. Su ámbito de especialidad conlleva la transposición terminológica de una cultura a otra más allá del espectro lingüístico, ya que países que comparten una misma lengua pueden no compartir los mismos aspectos jurídicos dentro de sus ordenamientos, como el caso de los países que conforman el espectro de

\footnotetext{
* Università degli studi di Macerata, Macerata, Itália.ruben_862@hotmail.com Orcid: https://orcid.org/0000-0002-9697-6942
} 
Hispanoamérica. En esta óptica, los problemas de traducción se antojan en el traductor objetivos ambiciosos de conquista en busca de la equivalencia formal. Algunos profesionales abogan por la intraducibilidad de los conceptos culturales fuertemente marcados presentes en la traducción jurídica, mientras que otros ven factible reflejar la equivalencia que debe evocar en la mente del lector el concepto. En la óptica de esta transposición cultural, la equivalencia cambiará en función de los objetivos y del carácter del documento. No sin razón, se ha pasado de la devota y exclusiva fidelidad al autor a hablar no solo de problemas y estrategias en traducción, sino también de las exigencias del lector meta. A este respecto, ténganse en cuenta, por ejemplo, cómo en traducción jurídica conceptos como el de Audiencia nacional, el recurso de amparo o las partes de una citación judicial en italiano carecerían de equivalencia completa, si bien ambas lenguas provengan de la misma familia lingüístico-jurídica y sus ordenamientos sean encuadrables en el seno del derecho romano-germánico.

A este respecto, la formación de los traductores es variopinta, pues la era del Web ha permitido no solo la entrada de profesionales provenientes de sectores ajenos, sino que la oferta de cursos de traducción online ha aumentado vertiginosamente, y es cuando menos, vasta. No sin razón, cada vez más entes o centros de formación privados se lanzan al mercado de la enseñanza de la traducción especializada, centrándose mayormente en aspectos lingüísticos y metódicos, pero dejando a un lado aspectos formativos preparatorios para el ejercicio de la profesión como el de las competencias del traductor. Existe un gran debate sobre la formación específica en traducción más allá del espectro del dominio de dos lenguas dada la sensación de traducibilidad que se tiene al dominar dos lenguas y al poseer diccionarios bilingües que apoyan el recorrido de transposición. Sin embargo, en traducción se transmiten conceptos, e incluso culturales, y no solo palabras, sobre todo en aquellos lenguajes con características tan fuertemente marcadas como el jurídico. De ello también da cuenta Márquez:

..hablar de traducción es hablar de procesos de comunicación estructurados, cuyo fin es romper las barreras que dividen las naciones y de este modo llevar de un lado a otro toda la concepción de cultura que se enmarca en cada una de ellas. (2011, p. 56)

\section{DEBATE SOBRE EL TRADUCTOR JURÍDICO JURISTA}

En materia de competencia, la del traductor jurídico no difiere significativamente de la del traductor de textos no sectoriales, ya que está compuesta por un conjunto de diferentes subcompetencias, esto es, el análisis del documento 
objeto de traducción, la recogida de información acerca de su naturaleza y de los recursos de consulta (subcompetencia instrumental) en primer plano; y en segundo, la traducción, la revisión y la edición (GARCÍA, 2001). No obstante, subyace una competencia específica dada la obligación del estudio del texto fuente para determinar, por ejemplo, las exigencias del macrotexto y microtexto y para localizar las posibles estrategias y técnicas de traducción (nótese, por ejemplo, la imposibilidad de traducir los títulos académicos, pues estos serán denominados en la lengua de llegada por el ministerio de competencia).

Mayoral (2005a) apunta al eterno debate sobre la competencia profesional del traductor jurídico jurista y no jurista. Y es en la primera fase de la traducción, el análisis del texto fuente, donde surge la exigencia de comprender el texto. A este respecto, los estudiosos no alcanzan una unanimidad sobre si el traductor jurídico necesita conocer la terminología o saber de derecho, sin perjuicio del deber de comprender en todo caso el documento. Soriano (2018) insiste en que no existe un consenso entre los estudiosos sobre si la formación de un traductor jurídico tiene que recaer tendencialmente en la esfera traductológica o jurídica. En relación con la formación del traductor, y según los estudiosos que cita, encontraríamos tres posturas: traductológica, intermedia y jurídica. La primera se basa en la falta de competencias comunicativas específicas por parte de los juristas y aboga por implantar una formación en derecho en los Estudios de Traducción. La postura intermedia, en cambio, defiende una formación lingüístico-jurídica con la intención de crear juristas y traductores competentes. Por último, los partidarios de la tercera opinan que solo los juristas pueden comprender plenamente los conceptos más complejos y por lo tanto, reproducirlos con la misma precisión en su lengua.

A favor del traductor jurista, entre las subcompetencias específicas encontramos la extralingüística, ya que la realidad que rodea el texto fuente y la cultura de la lengua de llegada requieren de unos conocimientos precisos que el traductor jurista podrá solventar en mayor medida. Paralelamente, todo proceso de traducción conlleva ciertos componentes psicólogicos, y es aquí donde la capacidad de síntesis y la confianza que debe poseer el traductor jurídico se verá acrecentada bajo una sólida formación en leyes. De hecho, el error a causa de la falta de bagaje jurídico del traductor no jurista puede conllevar responsabilidades mayores respecto a las de un texto no sectorial. No sin razón, en la fórmula de certificación que se ha de firmar para jurar un documento, el traductor jurado está obligado a dar fe de la vericidad del texto presentado.

Según Monzó (2008) la traducción facilitada por el traductor no jurista podría acarrear disputas y controversias. A este respecto, piénsese que la traducción de una 
ley en un país bilingüe en el otro idioma oficial tendrá el mismo peso jurídico que el texto fuente, como en los casos de Canadá o Suiza. Asimismo, el caso multilingüístico de la UE (Unión Europea) es cuando menos interesante, ya que todas las traducciones realizadas a partir del texto fuente poseen la misma validez legal, lo cual no lleva a hablar de «texto original» y «texto traducido», sino que desplega «efectos jurídicos en 28 ordenamientos jurídicos diferentes» (RUBIO, 2017, p. 310).

La praxis de la traducción de ciertos documentos de alcance internacional conlleva una minuciosa revisión y unas convenciones de estilo específicas emanadas por cada institución. Y es en tal proceso que la figura del tradutor jurista puede localizar problemas semánticos que los creadores del documento pasaron por alto, al mismo tiempo que ejerce un papel muy importante como desambiguador de los textos. Por el contrario, si este proceso se lleva a cabo por un traductor no jurista, se verá en la tesitura de interpretar leyes, lo cual conlleva un matiz irónico, pues no dispone de conocimientos sólidos en derecho y el organismo oficial de competencia solo procederá a la revisión en caso de disputa. Esta consideración nos conduce a que el traductor, independientemente de su formación, deberá reflejar el sentido del texto original a través de un cierto bagaje jurídico.

En cambio, a favor del traductor no jurista, Soriano (2018) evidencia que los juristas carecen de las competencias de los profesionales de la traducción, como «la profesional, interpersonal e instrumentali psicológica y estratégica, aunque sí habrán desarrollado parcialmente las competencias comunicativas y textual, (inter) cultural y temática» (p. 228). Además, conocerán el ordenamiento jurídico y la terminología de una de las dos lenguas de su combinación lingüística, pero no de la otra, por no mencionar el espectro cultural que recubre ambos idiomas para el que el traductor profesional tiene una cierta sensibilidad. Por último, el derecho se ocupa mayoritariamente del territorio nacional, lo cual no ayuda a solventar los problemas que puedan surgir del derecho comparado.

Con independecia de la condición o no de jurista, respecto a la comprensión del texto jurídico que el traductor debiera realizar, nos encontramos para Mayoral (2005a) con tres niveles de terminología, la cual no siempre se puede abordar con buenos recursos de consulta (nivel 1), sino que también es necesario disponer de elementos pragmáticos (nivel 2) o tener acceso a elementos extratextuales como «el ordenamiento jurídico, las intenciones del autor o de las partes» (p. 107) (nivel 3). Todo esto nos lleva a abogar por la formación jurídica del traductor en función de los principales núcleos temáticos del derecho y que indicamos a continuación, pues reflejan el punto de partida en la formación del traductor jurídico, pues su competencia 
principal pasa por conocer densamente no solo los niveles terminológicos, sino también el funcionamiento de ambos sistemas.

Un ejemplo concreto de terminología que encuadramos en el nivel 2 en el par de idiomas italiano-español es el Codice di Procedura Penale italiano, que encuentra respuesta en España en 'Ley de Enjuiciamiento Criminal', mientras que su traducción literal 'Código de procedimiento penal', por ejemplo, tendría validez en países como Colombia, Ecuador y Bolivia. Lo mismo sucede con la parte del proceso judicial que en italiano se denomina dibattimento di primo grado: en España se recoge en los códigos como 'vista oral', mientras que en otros países como Guatemala o México se encuentra en sentencias la traducción literal 'debate de primer grado'. Esto implica la necesidad de conocer ambos ordenamientos con el fin de analizar correctamente el texto fuente para satisfacer las necesidades del texto final. A tal propósito, destacamos en una tabla las principales ramas del derecho que el estudiante de traducción jurídica deberá integrar durante su recorrido formativo, con el objetivo de conocer sus principales semejanzas y diferencias, los géneros textuales más frecuentes que deberá afrontar durante su cometido y las instituciones regulares de derecho que subyacen en ellas, pues junto a los cargos son los elementos más temidos en este tipo de textos.

Tabla 1. Las ramas del derecho

\begin{tabular}{l|l}
\hline Derecho público & \multicolumn{1}{l}{ Derecho privado } \\
\hline Derecho constitucional & Derecho civil \\
Derecho político & Derecho mercantil \\
Derecho administrativo & Derecho internacional privado \\
Derecho penal & \\
Derecho procesal & \\
Derecho financiero o tributario & \\
Derecho laboral & \\
Derecho internacional público & \\
Derecho comunitario europeo & \\
\hline
\end{tabular}

\section{PAPELES Y COMPETENCIAS ESPECÍFICAS DEL TRADUCTOR JURÍDICO}

De acuerdo con el grupo de investigación PACTE (2019), existen disciplinas como la enseñanza de lenguas extranjeras que disponen de barómetros para la evaluación de competencias y aptitudes. De hecho, cabe pensar en el cuadro MCER y como en consecuencia el Instituto Cervantes prevé para sus examinadores orales 
parámetros detallados en escalas holísticas y analíticas. Sin embargo, la traducción no cuenta con un esquema reconocido a nivel internacional y la interdisciplinariedad que reina en los Grados o Diplomaturas de corte lingüístico es variada, pues asignaturas de traducción pueden ser troncales, obligatorias u optativas. El proyecto NACT (Nivelación de Competencias en la Adquisición de la Competencia Traductora) como prueba de sus primeros resultados adaptó los seis niveles previstos para la evaluación de lenguas a las competencias del traductor: a grandes rasgos el nivel A engloba las competencias básicas a través de textos no especializados tanto escritos en lenguaje estándar como con problemas de registro de diversos géneros textuales; el nivel B, en cambio, abarca textos no especializados o semiespecializados en al menos un ámbito profesional y por último, en el nivel $\mathrm{C}$ tienen cabida los textos especializados de al menos un ámbito profesional (PACTE, 2019). Téngase en cuenta que cada ámbito profesional en la traducción requerirá un desarrollo determinado de ciertas competencias: no sin razón, tomando en consideración el caso de la traducción jurídica, la decisión de traspasar los elementos dispares culturales en título de estudios de un cierto modo u otro podrá conllevar un grado diferente de admisión o convalidación por parte del organismo académico receptor.

A continuación, ilustramos detalladamente en una tabla los diversos papeles que desempeña el traductor jurídico según Mayoral (2005b) en función de sus habilidades y competencias:

Tabla 2. Los diferentes papeles y competencias del traductor jurídico según Mayoral

\begin{tabular}{ll}
\hline $\begin{array}{l}\text { PAPEL DEL } \\
\text { TRADUCTOR }\end{array}$ & COMPETENCIA \\
\hline Comunicador & $\begin{array}{l}\text { Facilitador en el proceso de comunicación para entender } \\
\text { culturas diferentes o conceptos abstrusos. }\end{array}$ \\
Lingüista [o & $\begin{array}{l}\text { Adopta términos nuevos frente a problemas terminológicos y } \\
\text { paraporciona asesoría paralingüística de sus lenguas de trabajo. }\end{array}$ \\
Jurista & $\begin{array}{l}\text { Asistente/auxiliar en campo jurídico a falta de juristas, como en } \\
\text { el caso de los países anglosajones'. }\end{array}$ \\
& $\begin{array}{l}\text { Simula un conocimiento vasto del texto aun no comprendiéndolo } \\
\text { en su totalidad, máxime cuando no es experto de la materia que } \\
\text { trata. }\end{array}$
\end{tabular}

1. Mayoral (2005b) menciona la falta de reconocimiento en los tribunales hacia los traductores cuando estos comunican e interpretan un documento jurídico, el cual es relegado solo a jueces y legisladores. Por otra parte, defiende que la actividad parajurídica del traductor, entendida como la asistencia que presta sin contar con una formación jurídica, está presente en la interpretación para los servicios públicos 
Investigador

Detective

Persona de negocios

Profesional

Servicio público

Benefactor

Cuidador

Notario

Mensajero

Evaluador de riesgos

Deontólogo

Aprendiz

Formador

Teórico
Capacidad continua para documentarse en la búsqueda de conocer lo desconocido bajo el juicio de los expertos.

A través de su curiosidad y su sentido común, el traductor pone en duda todo documento con validez jurídica que llega a sus manos.

Sus condiciones variarán en función de sus negociaciones con los comitentes, en busca de la rentabilidad de la profesión.

Capacidad para ofrecer buen servicio, reconocer las exigencias del cliente y actuar éticamente.

La profesión del traductor no se puede sustituir por la de otro profesional, por lo que la figura es incisiva y necesaria para el cliente.

Mediador por beneficiencia ante situaciones de riesgo o exclusión social en los inmigrantes, pues el traductor es la primera figura necesaria.

Figura de apoyo ante situaciones de ansiedad o crisis del cliente habida cuenta de su situación de vulnerabilidad lingüística.

El traductor como paranotario, ya que de forma fededigna firma un documento que reconoce como válido.

A través de la invisibilidad que se le otorga en esta profesión, el traductor es un mensajero en la comunicación.

Ponderación de la viabilidad de sus soluciones traductoras, dada la importancia de la transcendencia jurídica de las mismas.

Los criterios éticos se sitúan en la base de cada decisión traductora y la naturaleza de las mismas dependerá de su profesionalidad.

La finalización del documento pasa por la infatigable rutina de aprender nuevos conocimientos que propicien la perfección del texto.

La ambición lleva al traductor a explicar diferentes conceptos que conciernen la calidad de la traducción que se presta a realizar.

A través de su experiencia y de sus trabajos, extrapola conceptos y generalizaciones teóricas sobre la traducción y sus procesos. 
Las diversas herramientas a su disposición, como las informáticas, Artesano otorgan al producto acabado un cierto tono artesano dotado de la personalidad del traductor.

La traducción es el resultado de un proceso creativo por Creador parte del traductor, el cual aporta un margen de subjetivismo inadvertido,

Después de observar los papeles que recubre, detallaremos las competencias necesarias en el traductor para llevar a cabo con eficiencia y soltura su cometido. La competencia traductora «es la macrocompetencia que constituye el conjunto de capacidades, destrezas, conocimientos e incluso actitudes que reúnen los traductores profesionales y que intervienen en la traducción como actividad experta y que se desglosa en las subcompetencias» (Kelly, 2002, p. 14). Según la autora, estas son la subcompetencia comunicativa y textual, cultural, temática, instrumental profesional, psicofisiológica, interpersonal y estratégica:

a. La subcompetencia comunicativa y textual cubre las convenciones del texto en ambas lenguas y sus fases comunicativas activa y pasiva. El trabajo para alcanzarla cubriría el análisis y comprensión de los géneros y de las tipologías de textos a través de sus principales características y su posterior producción en ambas lenguas de trabajo.

b. La subcompetencia cultural comprende además del conocimiento del mundo del que dispone el traductor a través de esas lenguas de trabajo, creencias o mitos enmarcados en la cultura, entre otros. El método para adquirir esta subcompetencia pasaría por trabajar sobre tales conceptos, además de proporcionar información sobre las instituciones presentes en la cultura y sobre las relaciones texto-cultura.

c. La subcompetencia temática engloba los temas especializados que permiten al traductor la comprensión y el manejo del texto fuente. Su adquisición pasaría por una fase teórica que comprenda nociones básicas en el campo de la traducción y la interpretación, las estructuras de las disciplinas específicas (cabe pensar en la economía, o en nuestro caso, en el derecho) y sus fuentes de consulta.

d. La subcompetencia instrumental profesional comprende los instrumentos informáticos y las fuentes de consulta al alcance del traductor, así como el conocimiento de la práctica profesional por lo que concierne al código deontológico, la fiscalidad o la facturación, entre otros. Para ello, una formación práctica en terminología, en herramientas informáticas para traductores y en 
aspectos laborales como las obligaciones fiscales relativas a la práctica de la profesión, solventaría la carencia de esta subcompetencia.

e. La subcompetencia psicofisiológica cubre factores personales como la confianza que posee el traductor como figura profesional, su conciencia o la memoria, entre otros. El método para conseguir esta subcompetencia se basaría en fomentar la autoconfianza, junto al autoconcepto que tiene el traductor o intérprete de sí mismo, la atención y la memoria.

f. La subcompetencia interpersonal engloba la idoneidad de gestionar el trabajo con los demás compañeros de profesión en trabajos comunes y su relación con los clientes finales. Se podría trabajar acerca de casos prácticos sobre diferentes casos de comunicación traductor-cliente, la resolución de eventuales problemas o la conciencia de trabajo en equipo.

g. La subcompetencia estratégica comprende las técnicas que el profesional aplica a la disposición del encargo, al reconocimiento de problemas y a su solvencia y a la revisión de su crítica como profesional. Su estudio pasaría por métodos para desarrollar la identificación de problemas, su solución y la revisión de su autoconciencia como traductor.

Paralelamente, para Monzó (2008) existiría otra subcompetencia traductológica, descuidada durante la trayectoria académica del traductor, pero crucial en su desarrollo profesional: la relacionada con la gestión de proyectos (ligeramente diferente de la interpersonal y estratégica), pues si la posibilidad de manejar el problema y de solventarlo recae en la misma persona, el traductor se encontraría ante una «reivindicación profesional» de su trabajo (p. 9). Tal subcompetencia estaría compuesta por los conocimientos inherentes a la traducción (piénsese en la terminología o en las técnicas), por un carácter tendiente al del hombre de negocios como hemos indicado en la tabla anterior, y en último lugar, por una capacidad de crear relaciones tanto con otros traductores como con los clientes finales.

Por su parte, Márquez (2011) refleja otras competencias como la autónoma, que se basa en las decisiones independientes que el traductor toma durante el proceso de análisis y transposición; la flexibilidad, pues cada cliente deberá satisfacerse en función de sus exigencias y eso implicará, entre otras cosas, la adquisición de puntos de vista diferentes; y la tolerancia a la rutina, basada en la monotonía dictada por la exigencia de afrontar los encargos sedentariamente y frente a los instrumentos de trabajo.

Por último, consideramos necesaria la competencia específica en traducción jurídica que en estas líneas denominaremos relacional, esto es, la capacidad 
de vincular elementos de los ámbitos específicos de la intertextualidad y la interdisciplinariedad del derecho. Ambos conceptos reflejan la flexibilidad del lenguaje jurídico para impregnarse de otras disciplinas y de otros conocimientos previos. Con intertextualidad nos referimos a la miscelánea que en numerosas ocasiones el jurista y el traductor de textos legales deben realizar recogiendo todas las leyes citadas dentro de un texto con el objetivo de abarcar todas las casuísticas jurídicas posibles. Existen numerosos tipos de relaciones intertextuales detallados en el trabajo de Marinkovich (1998), sin embargo, destacamos la capacidad de relación y documentación que el traductor jurídico debe llevar a cabo en cada una de ellas. Por su parte, la interdisciplinariedad se encuentra presente vista la confluencia del lenguaje jurídico no solo con la lengua común sino con el lenguaje proveniente de otros sectores. Piénsese en las leyes sobre medioambiente, en donde el traductor necesitará contar con una formación específica más allá de la dictada por los manuales de derecho para relacionar los contenidos temáticos con su área correspondiente y reconocer los tecnicismos técnicos y colaterales propugnados por Serianni (2003) para su correcto tratamiento: mientras que los primeros abarcan el ámbito específico del derecho y del medioambiente, los segundos se usan a favor de una búsqueda refinada del lenguaje.

Todo ello indica la necesidad por parte del traductor jurídico de conocer correctamente las técnicas de traducción específicas, pues la elección pertinente de las mismas se presenta no solo como el resultado final de su trabajo, sino también como el reflejo de sus competencias. A continuación, exponemos brevemente un breve repaso de las técnicas que resaltarían las competencias del traductor jurídico en el resultado último de su trabajo:

a. La técnica de la traducción documental utiliza la glosa o las notas del traductor como método descriptivo o perifrástico para explicar el concepto que no dispone de una equivalencia plena en la otra lengua. Se puede incluir el término original entre paréntesis para una mayor comprensión por parte del jurista o se puede incluir en una nota a pie de página con una explicación pertinente. Esta técnica de traducción documental se suele utilizar con cierta recurrencia en la traducción jurada, donde la fiabilidad de la traducción conlleva destacar elementos que puedan ser inexactos, imprecisos o inteligibles. Algunos autores apuestan por esta técnica al no ver factible la traducción exacta de todos los términos como Vázquez y del Árbol (2016) u Orozco (2014), quien propone la traducción «negocio en participación de dos o más empresas» (p. 257) para el término joint venture. Otro ejemplo en la combinación italiano-español es la 
traducción del dulce siciliano cannolo, que en el diccionario Tam (2009) se recoge como 'rollo dulce de requesón'.

b. La técnica del préstamo consiste en transponer el término y mantenerlo inalterado o adaptarlo morfo-fonéticamente. Un ejemplo de adaptación sería la traducción de 'pizzero' del término italiano pizzaiolo, mientras que la Agenzia delle Entrate se dejaría inalterada al carecer una equivalencia plena. No obstante, se antoja inexacta e imprecisa, pues como bien señalan De Groot y Weston (en HOLL, 2012), no refleja el objetivo de comprensión que debiera tener un término traducido.

c. La técnica literal puede producir sinsentidos pues entre lenguas muy afines, como por ejemplo el italiano y el español, la proximidad léxica puede esconder errores semánticos. Un ejemplo citado en Cao (en BESTUÉ y OROZCO, 2011) sería la traducción de 'licencia' por representation, cuyo significado es diferente de nuestro término 'representación'.

d. La traducción léxica se perfila como la técnica pictórica que hace evocar en la mente del lector el concepto de manera inteligible. Un ejemplo sería el término italiano ravvedimento operoso en la traducción de una ley sobre medioambiente que se podría traspasar como 'corrección espontánea de la pena'. Otro caso estaría constituido por la traducción de las fiestas populares en otra lengua, donde normalmente se recurre a una pequeña descripción.

e. La técnica del equivalente contextual realiza su aparición cuando la traducción de un concepto tiene significado diferente en función de la realidad socio-pragmática. Orozco (2014) señala que el término inglés attorney puede ser traducido tanto por 'fiscal' como por 'participación social'.

f. La técnica del neologismo consiste en acuñar un término para designar una realidad para la que no se ha previsto un concepto preciso. No siempre es satisfactorio, pues no da pistas documentales sobre el posible significado del concepto.

g. La técnica del equivalente funcional es la más utilizada por los estudiantes de traducción al poner en acción los conocimientos jurídicos aplicados (DE GROOT, en VÁZQUEZy DELÁRBOL, 2016), pese a que crea falsos espejismos jurídicos. Ello se solucionaría con un análisis exhaustivo de ambos conceptos en los ordenamientos correspondientes, con el objetivo de descubrir las funciones y las realidades que recubren. Como ejemplo, Bestué y Orozco (2011) señalan que joint work se podría traducir como 'obra en colaboración', pues permite que los expertos «comprendan rápidamente el concepto y lo identifiquen» (190).

h. Por último, la tan codiciada técnica formal en traducción jurídica se verifica cuando dos realidades se presentan como intercambiables. Si bien no es rara, se 
debe recoger con cierta cautela, pues en un espectro tan culturalmente marcado se antoja complicado una correspondencia perfecta, incluso en dos realidades pertenecientes a la misma familia lingüístico-jurídica como en el caso del italiano y del español. Un caso concreto en esta combinación es la traducción del término italiano pubblico ministero por 'fiscal'.

\section{CONCLUSIONES}

A lo largo de estas líneas hemos realizado un recorrido sobre la formación jurídica del traductor de textos legales y sus competencias. De la reflexión se desprende la exhaustiva flexibilidad que debe poseer el traductor tanto por formación como por aptitud para poder realizar el trasvase lingüístico de una cultura a otra. En el lenguaje jurídico imperan conceptos y realidades de no fácil adaptación y se deberá realizar un atento estudio de las necesidades del texto original para plasmar a través de las técnicas de traducción los elementos requeridos en función del contexto y del carácter del documento. A tal respecto, ponemos en evidencia la importancia de una formación mínima en ambos ordenamientos, más allá del espectro lingüístico, para satisfacer la traducción de elementos específicos como la variación geográfica de la terminología o las principales instituciones reguladoras que se encuadran en las ramas del derecho. Por último, decretamos la necesidad apremiante de dedicar espacio en los cursos de traducción a las competencias preparatorias básicas del traductor como paso previo al ejercicio de la profesión en vez de centrar los módulos fundamentalmente en aspectos lingüísticos o formales.

\section{BIBLIOGRAFÍA}

BESTUÉ, C. y OROZCO, M. (2011). La necesidad en la reformulación en la traducción jurídica en la 'era de la automatización' de las traducciones. The Journal of Specialised Translation, 15, pp. 180-199.

HOLL, I. (2012). Técnicas para la traducción jurídica: revisión de diferentes propuestas, últimas tendencias. Hermeneus, (14), 191-216. Recuperado de http://diarium.usal.es/ irisaholl/files/2014/10/Hermeneus-2012-iris-holl.pdf

KELLY, DOROTHY A. (2002). Un modelo de competencia traductora: bases para el diseño curricular. Puentes, (1), 9-20. Recuperado de http://wpd.ugr.es/ greti/revistapuentes/pub1/02-Kelly.pdf 
MÁRQUEZ, D. A. (2011). Las once competencías del traductor: el perfil, ideal en servicios de traducción. Comunicación, Cultura y Política, (4), 53-68.

MARINKOVICH, J. (1998). El análisis del discurso y la intertextualidad. Boletín de Filología, 37 (2), 729-742. Recuperado de https://boletinfilologia.uchile.cl/index. php/BDF/article/view/21478/22776

MAYORAL, R. (2005a). ¿Cuánto derecho debe saber el traductor jurídico? En Esther Monzó y Anabel Borja (Eds.), La traducción y la interpretación en las relaciones jurídicas internacionales (pp. 107-112). Castellón: Universitat Jaume I.

MAYORAL, R. (2005b). El polifacetismo del traductor (jurídico y jurado). En Ana Cristina García de Toro e Isabel García Izquierdo (Eds.), Experiencias de traducción: reflexiones desde la práctica traductora (pp. 165-180). Castellón de la Plana: Publicaciones de la Universidad Jaume I.

MONZÓ, E. (2008). Derecho y traductología en la formación del traductor jurídico: una propuesta de formación virtual. Translation Journal, (12), 153-169. Recuperado de https://translationjournal.net/journal/44juridico.htm

OROZCO, M. (2014). Propuesta de un catálogo de técnicas de traducción: la toma de decisiones informada ante la elección de equivalentes. Hermeneus, (16), 233-264. Recuperado de https://recyt.fecyt.es/index.php/HS/article/view/33275

PACTE. (2019). Establecimiento de niveles de competencias en traducción. Primeros resultados del proyecto NACT. Onomázein, (43), 1-25.

RUBIO, M. (2017). La competencia traductora aplicada a la traducción jurídica en la Unión Europea. Entreculturas, (9), 303-315. Recuperado de http://entreculturasuma. comimagine.es/wp-content/uploads/2017/05/articulo18.MartaRubioOrtega. Entreculturas9.pdf

SERIANNI, L. (2003). Italiani scritti. Bolonia: Il Mulino.

SORIANO, G. (2018). La formación del traductor jurídico: análisis de la competencia traductora en traducción jurídica y propuesta de programa formativo. Quaderns, (25), 217-229. Recuperado de https://ddd.uab.cat/pub/quaderns/quaderns_a2018n25/ quaderns_a2018n25p217.pdf

TAM, L. (2009). Grande dizionario di spagnolo. Milán: Hoepli. 
VÁZQUEZ y DEL ÁRBOL, E. (2016). Técnicas de traducción jurídico-económica: evaluación y posibles aplicaciones de las notas y del traductor. Onomázein, (34), 55 69. Recuperado de http://onomazein.letras.uc.cl/Articulos/N34/34_7_Vazquez.pdf

Recebido: 6/7/2020

Aceito: $15 / 1 / 2021$

Publicado: 18/1/2021 